\title{
Effect of Surface Flux Boundary Conditions on Transient Suction Distribution in Homogeneous Slope
}

\author{
Gambo Haruna Yunusa ${ }^{1,2}$, Azman Kassim ${ }^{1 *}$ and Nurly Gofar ${ }^{3}$ \\ 'Department of Geotechnics \& Transportation, Faculty of Civil Engineering, Universiti Teknologi Malaysia, 81310 \\ UTM Johor Bahru, Johor, Malaysia; azmankassim66@gmail.com \\ 2Department of Civil Engineering, Faculty of Engineering, Bayero University Kano, PMB 3011, Kano, Nigeria \\ ${ }^{3}$ School of Civil \& Environmental Engineering, Nanyang Technological University, 50 Nanyang Avenue, Singapore
}

\begin{abstract}
Rainfall-induced slope failure is a common natural disaster that occurs frequently in many parts of the world. Many studies have been conducted on the effect of advancement of wetting front on reduction or elimination of the additional shear strength provided by matric suction in unsaturated soil. However, the inclusion of boundary flux condition such as evaporation in predicting soil suction for rainfall-induced slope failure analyses is still limited. Therefore, this study investigate the combined effect of two boundary flux (infiltration and evaporation) on transient suction distribution and hence the factor of safety (FOS) of a modelled slope which consist of slope height and horizontal distance of 5 and 47 m respectively with a slope angle of $21^{\circ}$. One year rainfall and evaporation data of a site in Johor Bahru, Malaysia were collected for the study and two months were selected to represent the wet and dry seasons based on the two predominant wind systems which brings rainfall in Malaysia (Northeast and Southwest monsoons). Soil samples were collected from the site for laboratory testing and the relevant soil properties required in the analyses were obtained. Initial soil condition was determined from Soil Water Characteristics Curve (SWCC) of the soil sample from the study area and these initial conditions were simulated at the beginning of each analysis to enable realistic condition of the soil to be obtained. The seepage analyses were conducted with Seep/w and the pore water pressure determined from the seepage analyses were used as input parameters in the slope stability analyses carried out with slope/w. The results of the analyses show that considering flux boundary condition has a great influence in maintaining negative pore water pressure in unsaturated soil especially during wet period when there is more water infiltrating the soil. Moreover, inclusion of evaporation in seepage analyses give more realistic pore water pressure and hence better prediction of FOS of the slope.
\end{abstract}

Keywords: Evaporation, Flux Boundary, Rainfall, Slope Stability, Suction Distribution

\section{Introduction}

Slope instability due to rainfall infiltration is one of the aspects of Geotechnical engineering that receives much attention over the past decades. It is a common and frequent natural disaster in many parts of the world particularly tropical climate countries experiencing period of intense or prolonged rainfall events ${ }^{1-7}$. Rainfall infiltration is the major triggering factor to slope failure in unsaturated soils because the failure mostly occurs during or after heavy rainfall ${ }^{8-13}$. Rainfall-induced slope failures usually occur as shallow slope failure, typically less than $3 \mathrm{~m}$ deep, with slip surface orientated parallel to the slope surface, especially in areas where a residual or colluvial soil profile has formed over a bedrock interface ${ }^{14,15}$. In tropical regions; water table exists at great depth and the soil above the water table typically exist in unsaturated condition, therefore; mostly these types of failure do not occur due to rise in water table rather it resulted from the

*Author for correspondence 
advancement of a wetting front and the reduction of the additional shear strength provided by the matric suction in the unsaturated soils ${ }^{15-17}$.

Apart from hydraulic properties of soils; the variation of negative pore-water pressure (suction) in unsaturated soils is also affected by climatic conditions such as rainfall characteristics (intensity and duration), rainfall pattern, evaporation and evapo-transpiration ${ }^{18}$. Water enters the soil by infiltration and leave by evaporation, transpiration and evapotranspiration. Therefore accurate prediction of evaporation has great application in predicting the pore-water pressure in the soil profiles for slope stability analysis $^{19}$.

Gofar et al. ${ }^{10}$ performed a parametric study to investigate the effect of ambient temperature, relative humidity and wind speed on rainfall infiltration rate, runoff and evaporation. They conclude that evaporation is sensitive to relative humidity and relatively insensitive to wind speed and also sensitive to ambient temperature lower than the soil temperature. Similarly they conclude that reliable saturation profile can only be achieved if accurate surface boundary condition was considered for analysis. Therefore, for accurate analysis of rainfall infiltration and seepage through soil it is important to consider the flux boundary condition because it is important in achieving a reliable saturation profile within a soil mass.

The quantity of rainfall that infiltrates the soil during a particular rainfall event depends on several factors such as initial soil moisture condition prior to a particular rainfall event, rainfall amount, saturated coefficient of permeability of the soil and other hydraulic properties of the soil. Since evaporation removes moisture from soil, it greatly affects the initial moisture condition and hydraulic properties of the soil. At the beginning of rainfall event when the matric suction of the near surface ground is high, there is high affinity of soil to water and almost all the rainfall will infiltrate into the soil, during which the infiltration capacity is higher than the saturated coefficient of permeability of the soil. The rainfall will continue to infiltrate until the infiltration capacity is equal to saturated coefficient of permeability $\left(k_{\text {sat }}\right)$. Beyond this point the rainfall infiltration is controlled by the saturated coefficient of permeability and according to Lee et al. ${ }^{20}$ the ratio of rainfall intensity $(I)$ to saturated coefficient of permeability $\left(k_{\text {sat }}\right)$ (i.e., $I / k_{\text {sat }}$ ) play important role on determining the critical rainfall pattern for slope stability analysis. Therefore, previous studies suggested different percentage of rainfall amount to be considered as infil- tration during numerical analysis, for example Gofar and $\mathrm{Lee}^{21}$; Rahardjo et al. ${ }^{22}$ and $\mathrm{Ng}$ et al. ${ }^{23}$ suggested $70 \%, 60 \%$ and $40 \%$ of rainfall as infiltration respectively.

Several researches have highlighted the role of rainfall infiltration in eliminating and/or destroying soil suction. Other researches consider the effect of other boundary flux on suction distribution, for example Rees and $\mathrm{Ali}^{24}$ have clarified the role of matured tree in increasing the soil suction and hence the factor of safety of a slope. Kassim et al..$^{25}$ considered a constant evaporation rate of $5 \mathrm{~mm} /$ day in predicting soil suction due to rainfall infiltration and concluded that inclusion of evaporation on numerical analysis give better prediction of suction distribution.

Therefore this study is aimed at investigating the effect of surface flux boundary condition on transient suction distribution for wet and dry conditions using typical tropical climate data. First, laboratory soil test was conducted on representative soil sample from the studied area and then numerical simulations were performed with Seep/W to assess the hydraulic responses of soil to variation of daily rainfall throughout the analyses period. Similar hydraulic responses considering the effect of evaporation were also assessed. Based on the pore water pressure obtained from these analyses; slope stability analyses were carried out for both conditions to determine the factor of safety of the slope due to the two scenarios.

\subsection{Flow of Water in Unsaturated Soil}

Unsaturated soil is a multiphase system with present of water and air in the voids and possesses four phases; i.e. solid, water, air and contractile skin (Air-water interface) and the pore water pressure is always negative relative to the pore air pressure ${ }^{16,17}$. The flow of water in unsaturated soils differs from that of saturated soils. In the former the coefficient of permeability varies with matric suction or degree of saturation and this function is assumed to be constant in the latter one. Apparently, the fundamental differences in the saturated and unsaturated flow equations are the changes in the suction dependent hydraulic conductivity, and the addition of a term to account for changes in the volumetric water content with time. It is evidenced that the saturated continuity of flow equation is specific of the unsaturated version of the equation.

The flow of water through unsaturated soils can be divided into two; the steady state flow and the transient flow, the governing equation in both types of flow combines Darcy's law and Continuity equation. In the steady state flow which is a constant water flow, there is no change 
in the hydraulic head at any point with time and the equation which is also called Poisson's equation is given as:

$$
\frac{\partial}{\partial x}\left(k_{x} \frac{\partial h}{\partial x}\right)+\frac{\partial}{\partial y}\left(k_{y} \frac{\partial h}{\partial y}\right)+q=0
$$

where $h$ is the hydraulic head, $k_{x^{\prime}} k_{y}$ are the coefficients of permeability of the soil along $x$ and $y$ coordinates; and $q$ is the applied unit flux.

In the second type of flow (i.e. the transient state flow) the hydraulic head changes as a function of time and is governs by Richard's equation. The equation considered changes in volumetric water content with time and is given as:

$$
\frac{\partial}{\partial x}\left(k_{x} \frac{\partial h}{\partial x}\right)+\frac{\partial}{\partial y}\left(k_{y} \frac{\partial h}{\partial y}\right)+q=\frac{\partial \theta_{w}}{\partial t}
$$

moreover, the right hand side of equation $2 a$ can be written as:

$$
\frac{\partial \theta_{w}}{\partial t}=m_{w}^{2} \rho_{w} g \frac{\partial h}{\partial t}
$$

where $\theta_{w}$ is the volumetric water content, $m_{w}^{2}$ is the coefficient of volumetric water change with respect to a change in negative pore-water pressure $\left(u_{\mathrm{a}}-u_{\mathrm{w}}\right)$ and is equal to the slope of the soil-water characteristic curve, $\rho_{w}$ is the density of water; and $g$ is gravitational acceleration.

In transient state flow the hydraulic head and the coefficient of permeability with respect to water are functions of the volumetric water content of the soil, this property turn the equation to be highly non-linear.

Therefore, equation $2 a$ illustrates that the sum of the rates of change of flows in the $x$ and $y$ directions and the external applied flux $(q)$ is equal to the rate of change of the volumetric water content with respect to time. Perhaps, for constant suction unsaturated situation the volumetric water content at any position does not change with time, therefore equation 1 can be the same as equation $2 a$ and hence equation 1 can also be applied for constant suction unsaturated situation.

\subsection{Shear Strength of Unsaturated Soils and Slope Stability}

Rainfall-induced slope failure is characterized with small depth-to-length ratios and it forms a failure plane which is parallel to the slope surface and hence the used of infinite slope stability analysis is justified. The stability of the slope which is usually expressed in form of factor of safety (FOS) can often be evaluated using a single layered infinite slope model ${ }^{14,26,27}$. The FOS is expressed as the ratio of shear strength of the soil and induced shear stress by loading.

According to Khalili and $\mathrm{Khabbaz}^{28}$, the shear strength of unsaturated soils can be determined using either twostress variable approach proposed by Fredlund et al. ${ }^{29}$ or the effective stress approach proposed by Bishop ${ }^{30}$. In the two-stress variables approach, the additional shear strength provided by matric suction was taken into consideration and the total stress in excess of pore air pressure and the matric suction are considered separately. The expression for the shear strength of unsaturated soil as proposed by Fredlund et al..$^{29}$ is given as:

$$
\tau=c^{\prime}+\left(\sigma_{n}-u_{a}\right) \tan \phi^{\prime}+\left(u_{a}-u_{w}\right) \tan \phi^{b}
$$

where $\tau$ is the shear strength, $c^{\prime}$ is the effective cohesion, $\varphi^{\prime}$ is the effective angle of internal friction, $\sigma_{\mathrm{n}}$ is the total normal stress on the plane of failure, $\left(\sigma_{n}-u_{a}\right)$ is the net normal stress, $u_{\mathrm{a}}$ is pore-air pressure, $u_{w}$ is pore-water pressure, $\left(u_{\mathrm{a}}-u_{\mathrm{w}}\right)$ is the matric suction and $\phi^{b}$ is the angle indicating the rate of change in shear strength relative to changes in matric suction, $\left(u_{\mathrm{a}}-u_{\mathrm{w}}\right)$.

In the effective stress approach the shear strength of the soil is determine on the basis of effective strength parameters $\left(c^{\prime}\right.$ and $\left.\varphi^{\prime}\right)$ and a single stress variable is proposed. This single stress variable is given as:

$$
\sigma^{\prime}=\left(\sigma-u_{a}\right)+\chi\left(u_{a}-u_{w}\right)
$$

where $\sigma^{\prime}$ is the effective stress, and $\chi$ is the effective stress parameter

The shear strength of the soil can therefore be written as:

$$
\tau=c^{\prime}+\left[\left(\sigma-u_{a}\right)+\chi\left(u_{a}-u_{w}\right)\right] \tan \phi^{\prime}
$$

Recently, Lu and Likos $(31,32)$ proposed a generalized effective stress approach for determining the shear strength of soil that unifies both saturated and unsaturated conditions as:

$$
\sigma^{\prime}=\left(\sigma_{n}-u_{a}\right)-\sigma
$$

where $\sigma^{s}$ is defined as the suction stress characteristic curve of the soil which according to Lu and Likos (32) can be obtained either by shear strenght test or by theoretical 
formulation and is expressed in form of normalised volumetric water content or degree of saturation as:

$$
\sigma^{s}=\frac{\theta-\theta_{r}}{\theta_{s}-\theta_{r}}\left(u_{a}-u_{w}\right)=\frac{S-S_{r}}{1-S_{r}}\left(u_{a}-u_{w}\right)
$$

where $\theta$ is the volumetric water content, $\theta_{\mathrm{r}}$ is the residual volumetric water content, $\theta_{s}$ is the saturated volumetric water content, $S$ is the degree of saturation, and $S_{\mathrm{r}}$ is the residual degree of saturation.

For unsaturated soil conditions, $\left(u_{w}<0\right)$ and

$$
\sigma^{s}=\frac{\theta-\theta_{r}}{\theta_{s}-\theta_{r}}\left(u_{a}-u_{w}\right)=\frac{S-S_{r}}{1-S_{r}}\left(u_{a}-u_{w}\right)<0
$$

For saturated soil conditions $\left(u_{w} \geq 0\right)$

$$
\text { and } \sigma^{s}=u_{w} \geq 0
$$

For determining the FOS of unsaturated slope, Cho and Lee (14) uses Fredlund et al. ${ }^{29}$ equation of shear strength and proposed an expression for FOS which is given as:

$$
F O S=\frac{c^{\prime}+\left(\sigma_{n}-u_{a}\right) \tan \phi^{\prime}+\left(u_{a}-u_{w}\right) \tan \phi^{b}}{\gamma_{t} z_{w} \sin \alpha \cos \alpha}
$$

where $\alpha$ is the slope angle, $\gamma_{\mathrm{t}}$ is the total unit weight of soil and $z_{\mathrm{w}}$ is the vertical depth of soil slice.

The FOS based on the generalized effective stress approach that unifies both saturated and unsaturated soil condition proposed by $\mathrm{Lu}$ and $\operatorname{Likos}^{31,32}$ can be written as:

$$
F O S=\frac{c^{\prime}+\left[\left(\sigma_{n}-u_{a}\right)-\sigma^{s}\right] \tan \phi^{\prime}}{\gamma_{t} z_{w} \sin \alpha \cos \alpha}
$$

\section{Material and Methods}

The studied area is in Johor Bahru, Malaysia and is roughly located at $1^{\circ} 34^{\prime} 11.73^{\prime \prime} \mathrm{N}$ and $103^{\circ} 38^{\prime} 41.61^{\prime \prime} \mathrm{E}$. The rainfall and evaporation data were obtained from the Department of Irrigation and Drainage (DID) Malaysia and it covers a period between January to December, 2009, among these data two months were eventually selected for the analyses; one month representing the wet period and the other month representing the dry period. This selection is on the basis of number of days of rainfall and intensity. Soil samples were collected from the studied area for laboratory soil testing. The methodology adopted in this study was divided into three stages including data collection, laboratory soil testing and seepage and slope stability analyses. The rainfall and evaporation data used in the analyses were obtained at the data collection stage. Series of laboratory test which includes Particle size distribution analysis, Atterberg limits, Specific gravity, Permeability test, Shear strength test and Pressure plate test were conducted at the laboratory soil test stage. Finally, seepage and slope stability analyses using finite element software (SEEP/W) and limit equilibrium software (SLOPE/W) were conducted at seepage and slope stability analyses stage respectively. The slope stability analysis was conducted using the pore water pressure obtained from the seepage analyses.

The laboratory tests were carried out based on the procedure and specifications outlined in British Standard and American Society for Testing and Materials (ASTM) as the case may be. The particle size distribution, atterberg limits and specific gravity tests were conducted for the soil classification purpose and were carried out based on the recommended procedure outlined in BS 1337 Part 2: $1990^{33}$.

The shear strength test was carried out to determine the soil input parameters for the slope stability analysis. This test was carried out in accordance with BS 1337 Part 8: 1990 . The effective shear strength parameters $\left(c^{\prime}\right.$ and $\varphi$ ) of the soils were determined by consolidated undrained (CU) triaxial test with pore-water pressure measurement. According to Fredlund el al. ${ }^{34}$ and Khalili and $\mathrm{Khabbaz}^{28}$, the equipment for measuring unsaturated soil parameter $\left(\varphi^{\mathrm{b}}\right)$ is generally expensive, sophisticated and this parameter is difficult and often impractical to be obtain because of the level of expertise required is often beyond that of many geotechnical engineering laboratories due to the strong non-linearity of $\varphi^{\mathrm{b}}$ with suction. Similarly according to Fredlund ${ }^{35}$ approximate soil properties are adequate for most analyses involving most practical problems. Hence, the angle $\left(\varphi^{\mathrm{b}}\right)$ which indicates the rate of change in the shear strength relative to the changes in matric suction, $\left(u_{\mathrm{a}}-u_{\mathrm{w}}\right)$ used in this study was estimated as $2 / 3$ of $\varphi^{\prime}$ because as rainfall infiltrates into the soil it results in matric suction reduction or even total elimination depending on soil moisture condition and rainfall intensity and according to Fredlund et al. ${ }^{34}$ the angle $\varphi^{\mathrm{b}}$ is equal to the effective angle of internal friction of the soil $\left(\varphi^{\prime}\right)$ up to the air entry value $\left(\mathrm{A}_{\mathrm{ev}}\right)$ of a soil and it decreases to $1 / 2-2 / 3$ of $\varphi^{\prime}$ beyond the $\mathrm{A}_{\mathrm{ev}}$ as the matric suction increases. 
The saturated permeability function $\left(k_{\mathrm{sat}}\right)$ of the soil, the soil water characteristic curve (SWCC) and the unsaturated hydraulic conductivity function of the soil are the input parameters for the seepage analysis. The $k_{\text {sat }}$ was obtained from falling head permeability test ${ }^{36}$.

The soil water characteristic curve (SWCC) was obtained from pressure plate test based on the procedure outlined in method B of ASTM D6836-02 ${ }^{37}$. Undisturbed soil samples obtained from the studied area was prepared for this test in accordance with the sample preparation procedure outlined in the ASTM. During the testing stage the pore water pressure $\left(u_{\mathrm{w}}\right)$ was maintained at atmospheric pressure, and the pore air pressure $\left(u_{\mathrm{a}}\right)$ inside the apparatus was raised by using air compressor to apply the suction via axis translation technique. Finally, the experimental data points obtained from the pressure plate tests were fitted using van Genutchen equation of SWCC. The relevant parameters of the SWCC include the saturated volumetric water content $\left(\theta_{\mathrm{s}}\right)$, the air entry value $\left(A_{\mathrm{ev}}\right)$, the residual water content $\left(\theta_{\mathrm{r}}\right)$ and the minimum suction at residual water content $\left(\psi_{\min }\right)$.

The unsaturated hydraulic conductivity function of the soil was obtained by prediction method as suggested by Leong and rahardjo ${ }^{38}$. The fitted SWCC and $k_{\text {sat }}$ were used to predict the unsaturated hydraulic conductivity of the soil using van Genuchten (1980) method ${ }^{39}$. The summary of the soil properties is presented in Table 1.

Table 1. Basic properties of the soil.

\begin{tabular}{|c|c|}
\hline Description & Properties \\
\hline Moisture content (\%) & 38 \\
\hline Liquid Limit (\%) & 57.5 \\
\hline Plastic Limit (\%) & 30.8 \\
\hline Plasticity Index (\%) & 26.7 \\
\hline Classification ( ${ }^{*}$ BSCS) & MHS \\
\hline \multicolumn{2}{|l|}{ Composition } \\
\hline Gravel (\%) & 0 \\
\hline Sand (\%) & 41 \\
\hline Silt (\%) & 24 \\
\hline Clay (\%) & 35 \\
\hline Specific gravity & 2.64 \\
\hline Unit weight, ã $\left(\mathrm{kN} / \mathrm{m}^{3}\right)$ & 19 \\
\hline Effective cohesion, c' (kPa) & 7 \\
\hline Effective friction angle, $\varphi^{\prime}\left(^{0}\right)$ & 30 \\
\hline$\varphi^{\mathrm{b}}\left(^{0}\right)$ & 20 \\
\hline $\begin{array}{l}\text { Saturated coefficient of permeability, } k_{\text {sat }} \\
(\mathrm{m} / \mathrm{s})\end{array}$ & $4.98 \times 10^{-7}$ \\
\hline
\end{tabular}

"BSCS - British Soil Classification System
The particle size distribution curve, the SWCC and the unsaturated hydraulic conductivity function of the tested soil are presented in Figures 1, 2, and 3 respectively. The relevant SWCC parameters are summarized in Table 2.

The seepage analyses were carried out using finite element software SEEP $/ \mathrm{W}^{40}$. The analyzed slope is a homogenous slope of $5 \mathrm{~m}$ thickness and $47 \mathrm{~m}$ horizontal distance with a slope angle of $21^{\circ}$ as shown in Figure 4. The seepage model comprised of 1111 nodes and 1000 quadrilateral mesh elements to represent the slope profile. A fine quadrilateral element mesh of $0.25 \mathrm{~m} \times 1 \mathrm{~m}$ were used in the numerical model to appropriate simulates the soil condition. The slope stability analyses were carried out using a limit equilibrium software SLOPE/ $\mathrm{W}^{41}$ with pore water pressure determined from the transient seepage analyses, the shear strength parameters of the soil and the angle which indicates the rate of change in the shear strength relative to the changes in matric suction $\left(\varphi^{\mathrm{b}}\right)$ as input parameters. Morgenstern-Price method satisfying equations of static and considers both shear and normal inter slice forces was used to compute the FOS of the infinite slope. Since determining the position of critical slip surface with lowest FOS is one of the challenging tasks in stability analysis of a slope, entry and exit method in which locations where the trial slip surfaces will likely enters the ground surface and where they exit was used at the initial stage and determined the FOS of the slope. Several combinations of different entry and exit points were compared and the one which give the lowest FOS was adopted. Similarly another method called auto locate was also used to locate the critical slip surface, after the results were compared, entry and exit method was adopted in the subsequent analyses because it gives the lowest FOS.

\subsection{Rainfall and Evaporation Data}

Rainfall in Malaysia occurs throughout a year and is formed by two major wind systems; the Northeast monsoon, which occurs from November to March and is associated with heavy rainfall and the Southwest monsoon which occurs from May to September and is dry period throughout the country. April and October form transitions between the two monsoons called inter-monsoon and bring heavy rainfall.

The daily rainfall and evaporation data of the studied area are presented in Figure 5 while the total monthly and the maximum daily rainfall are presented in Figure 6. Two months were selected for the analyses; one month with 


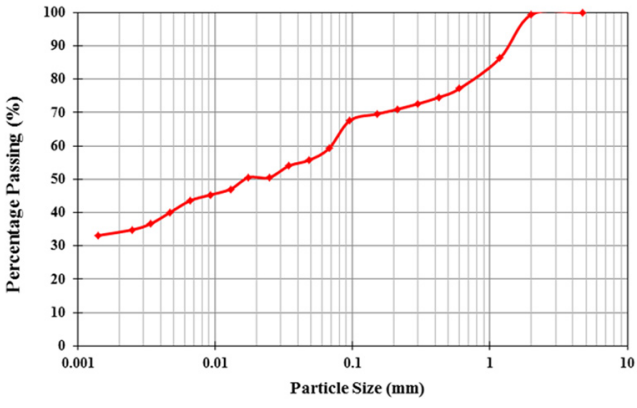

Figure 1. Particle size distribution curve of the soil from the study area.

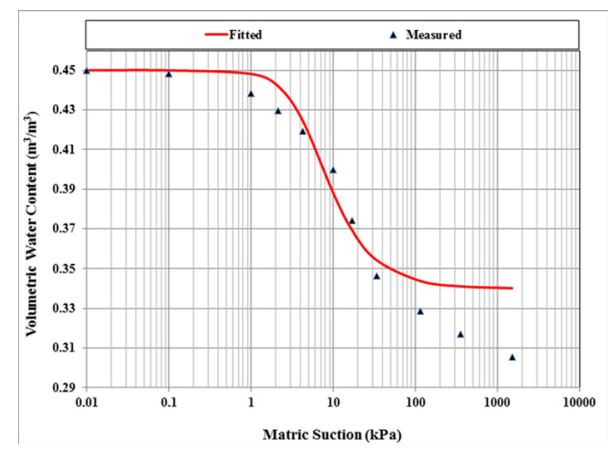

Figure 2. Soil Water Characteristic Curve (SWCC) of the soil.

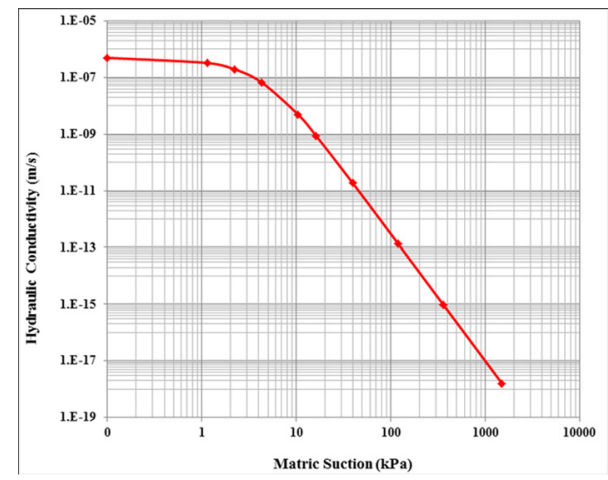

Figure 3. Hydraulic Conductivity function of the soil.

Table 2. Basic unsaturated properties of the soil.

\begin{tabular}{lc}
\hline Parameter & Properties \\
\hline Saturated water content, $\theta_{\mathrm{s}}\left(\mathrm{m}^{3} / \mathrm{m}^{3}\right)$ & 0.45 \\
Residual water content, $\theta_{\mathrm{r}}\left(\mathrm{m}^{3} / \mathrm{m}^{3}\right)$ & 0.34 \\
Air entry value, $A_{\mathrm{ev}}(\mathrm{kPa})$ & 2.9 \\
Minimum suction at residual water content $(\mathrm{kPa})$ & 32 \\
Best-fitting Parameters & \\
$A$ & 0.19 \\
$N$ & 2.08 \\
$M$ & 0.52 \\
\hline
\end{tabular}

Vol 7 (12) | December 2014 | www.indjst.org

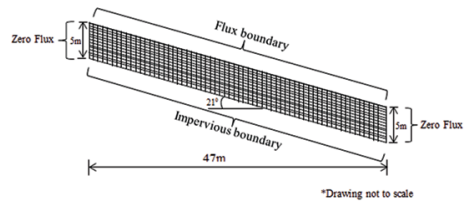

Figure 4. Idealized slope model.

more number of days of rainfall to represent wet period and another month with less number of days of rainfall to represent dry period. Based on this criteria April and July were eventually selected to represent wet and dry periods respectively.

The establishment of initial condition is very important in seepage and slope stability analyses, because it provide information on the soil condition before any rainfall event. To simulate the actual wet period the analyses commenced from $19^{\text {th }}$ February because the soil is assumed to be dry before $19^{\text {th }}$ February due to many days without rainfall infiltration and the initial condition was created by assigning the residual water content from the SWCC, which was obtained by drawing a tangent from the inflection point of the curve and another tangent from the tail of the curve. The intersection point of these two tangents give residual water content at $y$-axis and minimum suction at the residual water content in $x$-axis (Figure 2). Similarly, to simulate the dry condition; the analysis began from the $6^{\text {th }}$ June because the soil is assumed to be dry on that day. The rainfall and evaporation data for the two analyses period and wet and dry months were shown in Figure 7.

\section{Results and Discussions}

\subsection{Seepage Analysis}

A finite element computer program (SEEP/W) was used in the seepage analyses and determine the pore water pressure due to rainfall infiltration using rainfall and evaporation data. Seventy percent of the rainfall amount was considered as infiltration in to the soil slope as suggested by Gofar and Lee ${ }^{42}$ while the remaining $30 \%$ was assumed to be surface run-off. The selection of $70 \%$ of rainfall as infiltration seems to be conservative compared to suggestions by other researches such as Rahardjo et al. ${ }^{22}$ which sugeested $60 \%$ infiltration and $40 \%$ runoff and $\mathrm{Ng}$ et al. ${ }^{23}$ which suggested $40 \%$ infiltration and $60 \%$ runoff. Prior to the actual transient analyses several analyses were conducted to simulate the initial condition of soil 


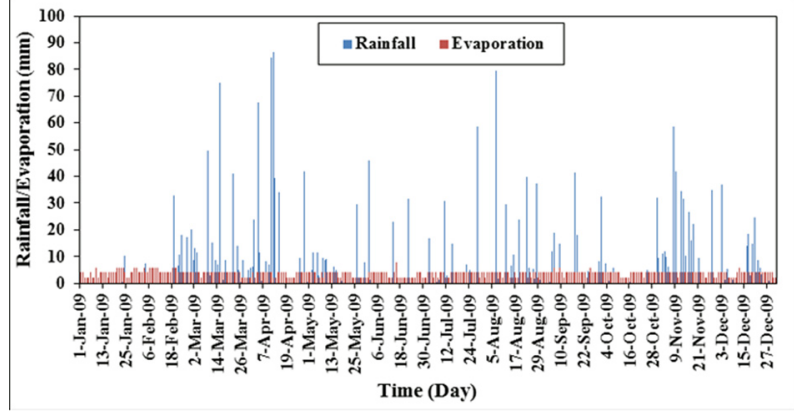

Figure 5. Rainfall and evaporation data of the study area.

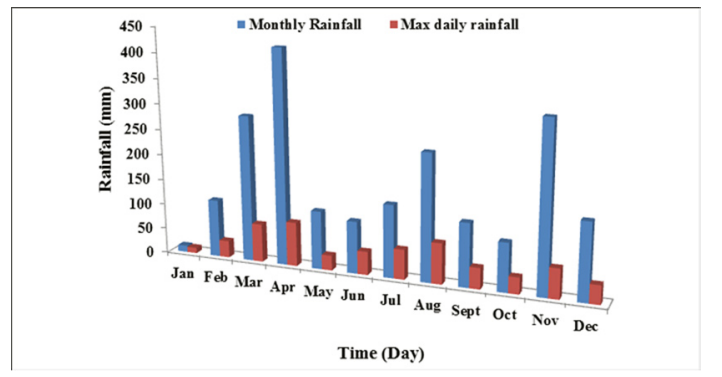

Figure 6. Maximum daily and total monthly rainfall of the study area.

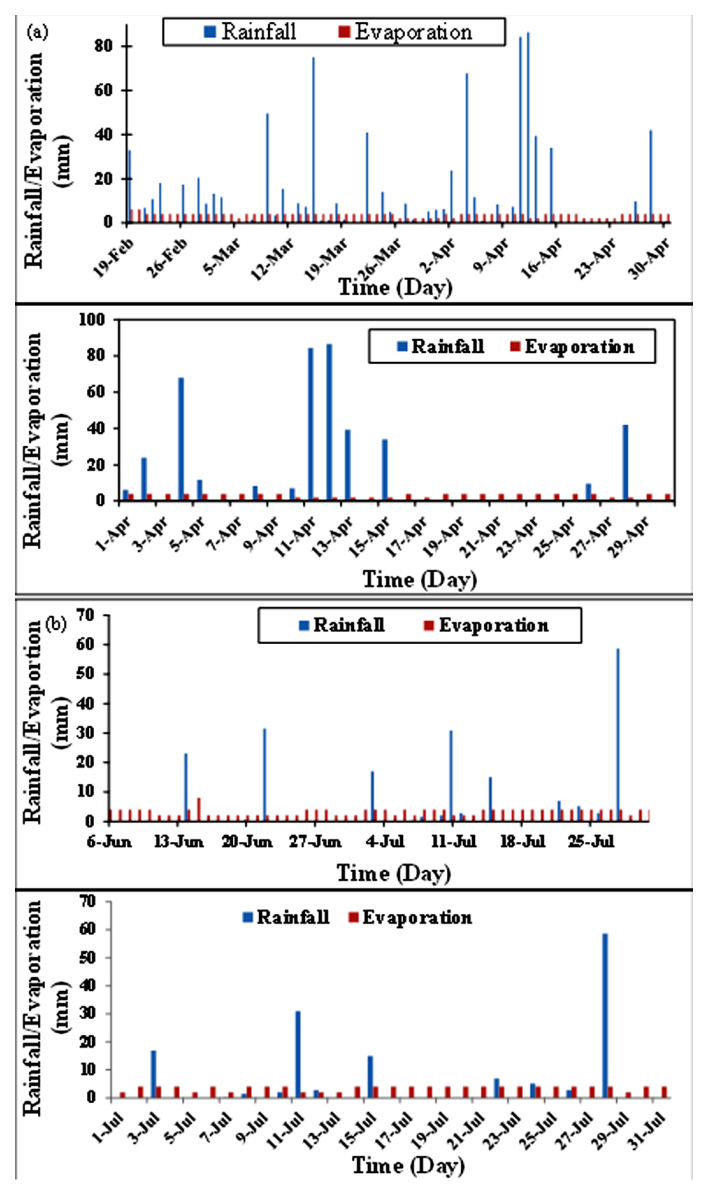

Figure 7. Rainfall and Evaporation data (a) Wet condition, (b) Dry condition. before the test, and this was terminated when the suction value obtained is approximately equal to the suction at residual water content, this is in accordance with suggestion by Yang et al..$^{43}$ that the limiting suction of any soil can be estimated from minimum suction corresponding to the residual water content, $\left(\psi_{\min }\right)$ in the SWCC of the soil.

\subsection{Transient Suction Distribution with Time}

The soil suction (negative pore water pressure) were determined at three different points (i.e. $0.5 \mathrm{~m}, 1.0 \mathrm{~m}$ and $1.5 \mathrm{~m}$ ) from the surface of the analyzed infinite slope. The results obtained from the transient seepage analyses were expressed in form of suction versus time and suction versus depth. As stated earlier the analyses for the wet condition begins from $19^{\text {th }}$ February while that of dry condition from $6^{\text {th }}$ June, this is to enable an appropriate simulation of initial soil condition before the selected months. The suction distribution with time due to rainfall infiltration and rainfall infiltration \& evaporation for wet condition, wet month, dry condition and dry month were presented in Figure 8. Figure $8 a$ presents the transient seepage analysis results for the wet condition. From this Figure; the pore water pressure increases at all depths which resulted in decrease in suction due to continuous rainfall infiltration. The response of pore water pressure due to rainfall infiltration depends on rainfall intensity and the effect is more noticeable when the intensity is high. The pore water pressure changes quickly from the initial condition value $(32 \mathrm{kPa})$ to below $10 \mathrm{kPa}$. The $33 \mathrm{~mm}$ rainfall on $19^{\text {th }}$ February resulted in decrease in suction at $0.5 \mathrm{~m}$ depth from $32 \mathrm{kPa}$ to $27 \mathrm{kPa}$ and from $32 \mathrm{kPa}$ to $30 \mathrm{kPa}$ due to rainfall infiltration and infiltration and evaporation respectively. But the suction was maintained at $1.0 \mathrm{~m}$ and $1.5 \mathrm{~m}$ because the infiltrated water does not reach these depths. The suction at $1.0 \mathrm{~m}$ begins to respond to infiltration after $18 \mathrm{~mm}$ rainfall on $23^{\text {rd }}$ February and after $8.5 \mathrm{~mm}$ on $1^{\text {st }}$ March when the effect of evaporation was considered. Similarly, the suction at $1.5 \mathrm{~m}$ changes on $1^{\text {st }}$ March due to infiltration and due to $11.5 \mathrm{~mm}$ rainfall on $3^{\text {rd }}$ March when evaporation was considered. The suction at these depths nearly approaches equal magnitude after $6^{\text {th }}$ March even though there was no rainfall for three consecutive days. The possible explanation of this is the soil moisture in the near surface ground is removed by evaporation and this enables the moisture at downward depths to be maintained. 


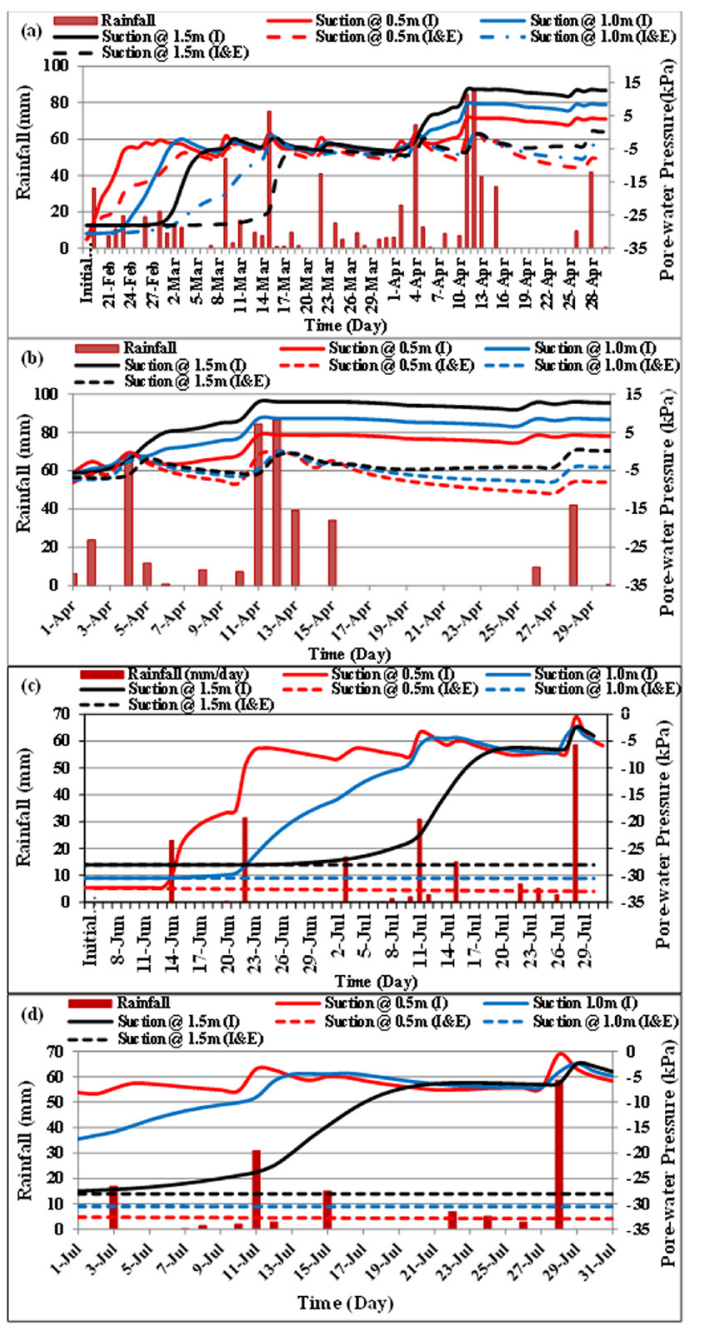

Figure 8. Variation of suction with time due to rainfall infiltration and infiltration + Evaporation (a) Wet condition (b) Wet month (c) Dry condition (d) Dry month.

The result of the transient seepage analysis for the selected wet month was presented in Figure $8 b$ and there was a total of $421.60 \mathrm{~mm}$ of rainfall in the month and a maximum daily rainfall of $86.50 \mathrm{~mm}$ (Figure 6) which are the highest monthly rainfall intensity and maximum daily rainfall intensity throughout the year (Figure 6). The negative pore water pressure (suction) at the beginning of this month (initial condition for the month) is nearly similar due to rainfall infiltration alone but it varies in order of magnitude of 1 due to infiltration and evaporation. In this month there are three days of rainfall of high intensity, $4^{\text {th }}$ April $(67.8 \mathrm{~mm} /$ day $), 11^{\text {th }}$ April $(84.4 \mathrm{~mm} /$ day $)$ and $12^{\text {th }}$ April $(86.50 \mathrm{~mm} /$ day). These rainfall intensities have resulted in total elimination of negative pore water pressure in the modeled slope when rainfall infiltration alone was considered and they resulted in very low matric suction (close to zero) when infiltration and evaporation were considered together. After the high intensity rainfall of $12^{\text {th }}$ April the suction begins to redistribute again but in slow face until $28^{\text {th }}$ April when $42 \mathrm{~mm} /$ day rainfall causes a noticeable increase in the pore water pressure.

The result of analyses for the dry condition was shown in Figure $8 c$ which started from $6^{\text {th }}$ June. The negative pore water pressure was maintained throughout the period of analyses. It was towards the end of the analyses period the negative pore water pressure approaches zero due to high intensity rainfall of $58.7 \mathrm{~mm} /$ day that occurred on $28^{\text {th }}$ July this is when the infiltration was considered alone, however, when the effect of evaporation was incorporated in the analyses the negative pore water remained nearly constant throughout the analyses period.

Unlike in the case of wet month (April) where rainfall infiltration causes the initial soil condition at beginning of the month to be nearly the same; the initial soil condition (with and without the effect of evaporation) at the beginning of the dry month is totally different as shown in Figure $8 d$. This occurred as a result of days of rainfall in the analyses period (i.e. from $6^{\text {th }} J$ une to $30^{\text {th }}$ June). The changes in negative pore water pressure is more noticeable at $0.5 \mathrm{~m}$ depth than $1.0 \mathrm{~m}$ depth but negative pore water pressure at $1.5 \mathrm{~m}$ depth only begins to change rapidly after $13^{\text {th }}$ July and this is due to rainfall intensity of $30.9 \mathrm{~mm}$ on $11^{\text {th }}$ July which infiltrates up to $1.5 \mathrm{~m}$ depth and affect the negative pore water pressure at this depth. Other less intense rainfall after $11^{\text {th }}$ July causes the suction at $1.5 \mathrm{~m}$ to approaches the values of suction at other depth. This is a clear indication that because of less number of days of rainfall evaporation affect the near surface soil by removing the soil moisture and making its affinity toward water absorption to increase and when there is rainfall infiltration it easily penetrates the soil and because the soil moisture downward are less affected by evaporation their soil moisture is maintained, therefore movement of water at these depths occur very slowly.

\subsection{Transient Suction Distribution with Depth}

The variation of suction with depth is presented in Figure 9. Two initial conditions were shown in this Figure; the first one represent the initial condition of the soil prior to any rainfall event (i.e. beginning of the analyses) while the second initial condition ( $31^{\text {st }} \mathrm{March} / 30^{\text {th }}$ June) marked the initial condition of the selected wet/dry month. At 
the beginning of the analyses, the suction variation with depth only affect shallow depths in both cases but as water continues to infiltrates, the negative pore water pressure at other depths were also affected. In Figure $9 a$ the negative pore water pressure was eliminated at $3.0 \mathrm{~m}$ depth due rainfall infiltration on $31^{\text {st }}$ March but it follows the initial condition pattern from $3.0 \mathrm{~m}$ downward when the effect of evaporation was considered in the analysis. The intense rainfall events on $11^{\text {th }}$ and $12^{\text {th }}$ April (i.e. $84.4 \mathrm{~mm}$ and $86.5 \mathrm{~mm}$ ) resulted in total elimination of the negative pore water pressure at all the depths due to the effect of rainfall infiltration, however, when the effect of evaporation was considered there was presence of negative pore water pressure at $1.5 \mathrm{~m}$ depth up to the end of the month. The negative pore water pressure from $0.5 \mathrm{~m}$ to $1.5 \mathrm{~m}$ depth on $28^{\text {th }}$ April is greater than the negative pore water pressure values on $12^{\text {th }}$ April due the effect of evaporation because of increase in number of days without rainfall after $15^{\text {th }}$ April.

The negative pore water pressures in the dry month (Figure 9b) were maintained throughout the analyses

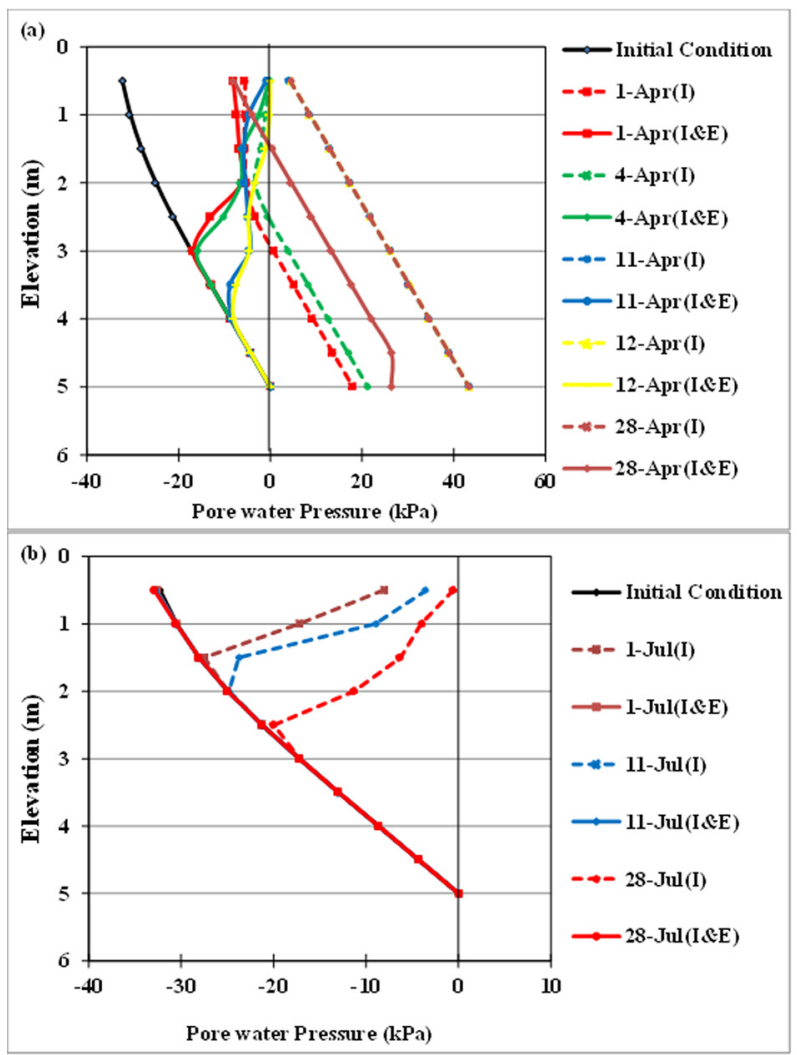

Figure 9. Variation of Suction with depth (a) Wet month (b) Dry month. period, though it approaches a value close to zero (i.e. elimination of the negative pore water pressure) towards the end of the month. Similarly the changes in negative pore water pressures were noticeable up to $2.5 \mathrm{~m}$ depth from the surface of the analyzed slope with effect of rainfall infiltration alone, these negative pore water pressures were maintained when the effect of evaporation was considered, in fact it follows the pattern of the initial condition of the soil.

\subsection{Slope Stability Analyses}

The slope stability analyses were carried out using a limit equilibrium software (SLOPE/W). The transient suction distribution taken from Seep/W analyses were exported to Slope/W for slope stability analyses. The obtained results are expressed in the form of FOS versus time and are presented in Figure 10. This Figure generally indicates how the changes in suction distribution due to rainfall infiltration and rainfall infiltration and evaporation affect the factor of safety of the slope. The FOS for the wet condition (Figure 10a) was nearly constant for both rainfall infiltration and rainfall infiltration and evaporation before $20^{\text {th }}$ March, this is because the infiltrated water does not reached the depth of slip surface it only affects some shallow depth as shown in Figure $9 a$. However, after rainfall on $21^{\text {st }}$ March the FOS due to the effect of rainfall infiltration continues to drop even with other smaller intensity rainfalls. On the other hand the changes in the FOS due to the effect of rainfall infiltration and evaporation was very small until the two high intensity rainfalls that occurred on $11^{\text {th }}$ and $12^{\text {th }}$ April which causes the FOS to drop below 2.0. In Figure $10 b$ the FOS for the dry condition increases at the beginning of the month in both cases but later it drops due changes in the soil suction resulted from rainfall infiltration and it continues to decrease throughout the period of analyses. The possible explanation of this is, in the dry month there is less moisture in the soil and since the rainfall infiltration is not as frequent as in the wet month, the rainfall infiltrates the soil easily and other subsequent rainfall may also continue to infiltrates the soil and hence causes continues decrease in the FOS of the analyzed slope throughout the analyses period. However, the FOS due to the effect of rainfall infiltration and evaporation remained relatively constant throughout the period of analysis. This shows how the effect of evaporation on days without rainfall infiltration neutralizes the effect of rainfall infiltration in the dry period. 


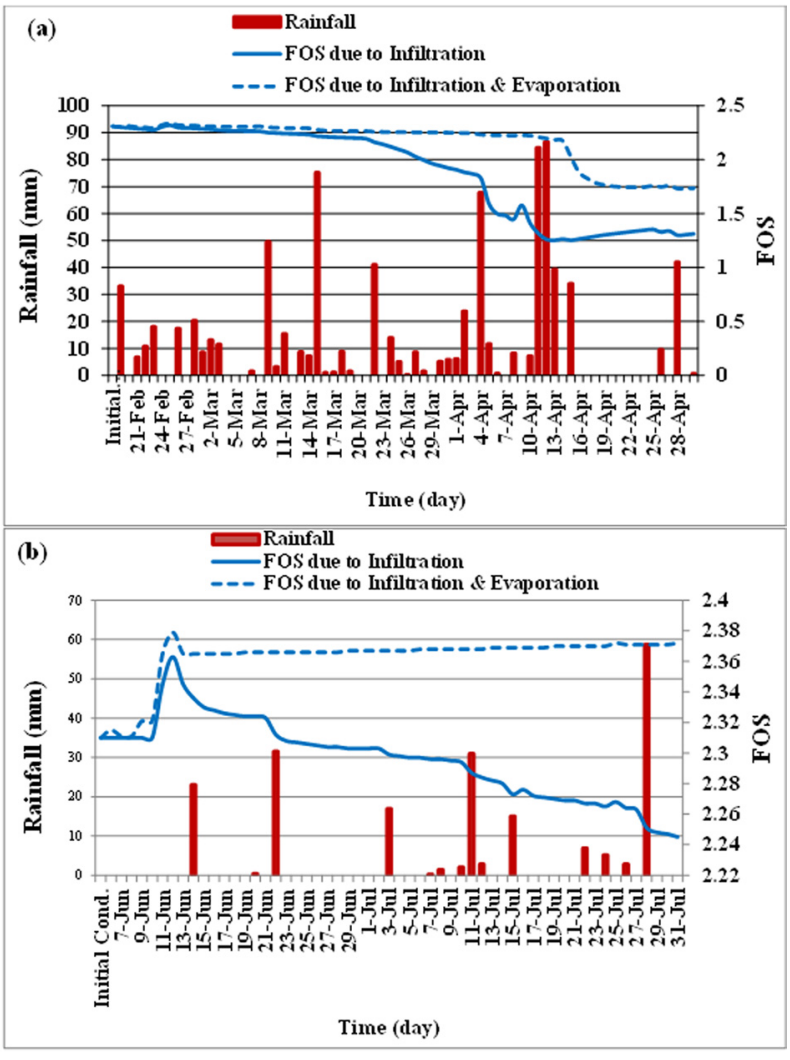

Figure 10. Variation of Factor of safety with time (a) Wet condition (b) Dry condition.

\subsection{Seasonal Variation of Suction Distribution and Factor of Safety of the Slope}

The variations of soil suction with time due to wet and dry month were shown in Figure 11. The effect of evaporation mostly affects the near surface soil; hence the first $0.5 \mathrm{~m}$ depth was selected for comparison of seasonal suction variation between wet and dry months. The negative pore water pressure was eliminated during the wet period but it was maintained in the dry period when the effect of rainfall infiltration alone was considered, however, when the effect of evaporation was considered the variation of suction with time only occurs in the wet month but the negative pore water pressure remained constant (with very insignificant changes in the soil suction) in the dry month.

Figure 12 shows the seasonal variation of the FOS of the analyzed slope. The patterns of seasonal variation of FOS between the wet and dry conditions are similar to that of seasonal suction distribution because increase/

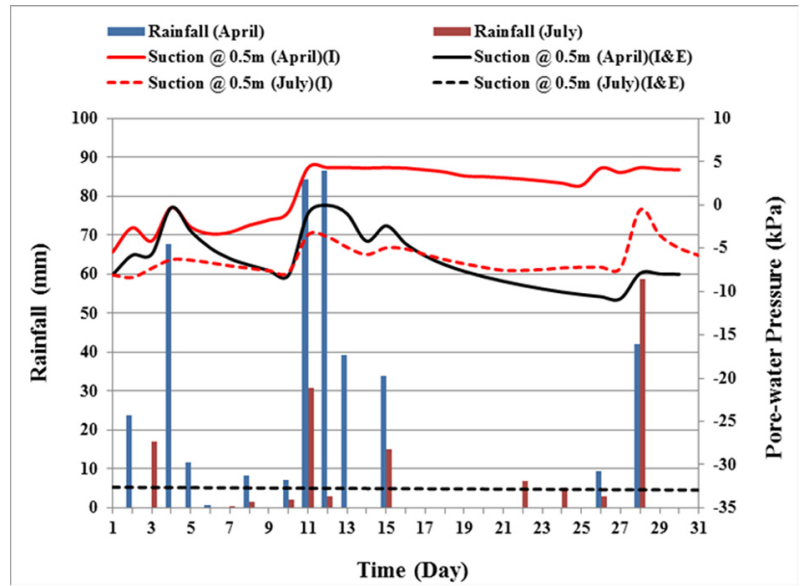

Figure 11. Suction Distribution due to Seasonal variation.

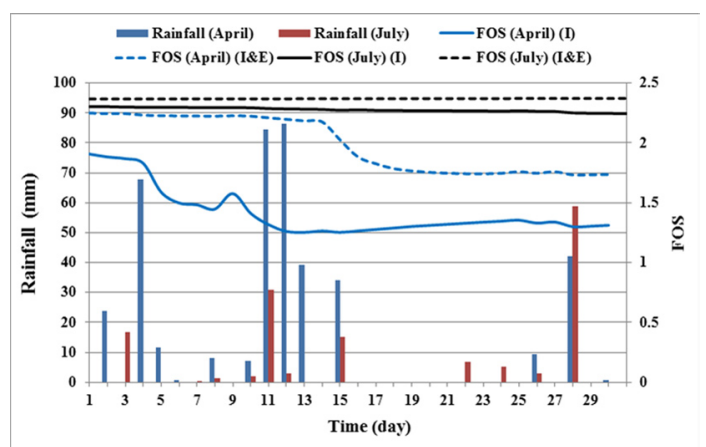

Figure 12. Variation of Factor of Safety with Season.

decrease in soil suction results is increase/decrease in the soil shear strength and therefore affects the FOS of the slope. In the case of wet condition the FOS due to rainfall infiltration and rainfall infiltration and evaporation at the beginning of the month varies. The variations occurred as a result of more moisture in the soil due to rainfall infiltration and less soil moisture when evaporation was considered. The variation of FOS in the dry month remained constant compared to the wet month because the drop in the FOS value is very small when compared to that of wet month.

\section{Conclusion}

Numerical analysis was conducted to investigate the effect of flux boundary condition on transient suction distribution in homogenous slope. One year rainfall and evaporation data were collected and used in the numerical analyses. This study shows that considering the effect of rainfall alone in predicting negative pore water 
pressure for rainfall-induced slope failure results in total elimination of negative pore water pressure during wet season and this may lead to unrealistic FOS of the slope. However, inclusion of other flux boundary condition such as evaporation gives more realistic negative pore water pressure which is good agreement with measured soil suction in the field. The variation of negative pore water pressure is more pronounced in the near surface soil because it is more affected by the flux boundary condition.

\section{References}

1. Au SWC. Rain-induced slope instability in Hong Kong. Engineering Geology. 1998; 51(1):1-36.

2. Brand EW. Landslides in Southeast Asia: a State-of-the-art Report. 4th International Symposium on Landslides; 1984; Toronto.

3. Dai F, Lee CF, Wang S. Analysis of rainstorm-induced slide-debris flows on natural terrain of Lantau Island, Hong Kong. Engineering Geology. 1999; 51(4):279-90.

4. Godt JW, Şener-Kaya B, Lu N, Baum RL. Stability of infinite slopes under transient partially saturated seepage conditions. Water Resources Research. 2012; 48(5).

5. Rahardjo H, Rezaur RB, Leong EC. Mechanism of Rainfallinduced slope failures in tropical regions. The 1st Italian Workshop on Landslides; 2009 Jun 8-10; Napoli, Italy.

6. Rahimi A, Rahardjo H, Leong E-C. Effect of hydraulic properties of soil on rainfall-induced slope failure. Engineering Geology. 2010; 114(3-4):135-43.

7. Zhang LL, Zhang J, Zhang LM, Tang WH. Stability analysis of rainfall-induced slope failure: a review. Proceedings of the Institution of Civil Engineers-Geotechnical Engineering. 2011; 164(GE5):299-316.

8. Bai S, Wang J, Thiebes B, Cheng C, Yang Y. Analysis of the relationship of landslide occurrence with rainfall: a case study of Wudu County, China. Arabian Journal of Geosciences. 2013.

9. Cho SE, Lee SR. Instability of unsaturated soil slopes due to infiltration. Computers and Geotechnics. 2001; 28(3): 185-208.

10. Gofar N, Lee LM, Kassim A. Effect of Surface Boundary Condition on Rainfall Infiltration. Jurnal Teknologi. 2006; 44(B).

11. Kassim A, Gofar N, Mokhtar N, Lee ML. The Effect of Transient State Rainfall on Stability of a Residual Soil Slope. International Conference on Slope; 2006 Aug; Malaysia. p. 12.

12. Ng CWW, Shi Q. A numerical investigation of the stability of unsaturated soil slopes subjected to transient seepage. Computers and Geotechnics. 1998; 22(1):1-28.
13. Rahardjo H, Li XW, Toll DG, Leong EC. The effect of antecedent rainfall on slope stability. Geotechnical and Geological Engineering. 2001; 19:371-99.

14. Cho S, Lee S. Evaluation of Surficial Stability for Homogeneous Slopes Considering Rainfall Characteristics. Journal of Geotechnical and Geoenvironmental Engineering. 2002; 128(9):756-63.

15. Rahardjo H, Lim TT, Chang MF, Fredlund DG. Shear strength characteristics of a residual soil with suction. Canadian Geotechnical Journal. 1995; 32:17.

16. Fredlund DG, Rahardjo H. Soil Mechanics for Unsaturated Soils. John Wiley \& Sons, Inc; 1993.

17. Fredlund DG, Rahardjo H, Fredlund MD. Unsaturated Soil Mechanics in Engineering Practice. John Wiley \& Sons, Inc.; 2012.

18. Zhan T, Ng C. Analytical Analysis of Rainfall Infiltration Mechanism in Unsaturated Soils. International Journal of Geomechanics. 2004; 4(4):273-84.

19. Weeks B, Wilson GW. Prediction of evaporation from soil slopes. Canadian Geotechnical Journal. 2006; 43(8):815-29.

20. Lee LM, Gofar N, Rahardjo H. A simple model for preliminary evaluation of rainfall-induced slope instability. Engineering Geology. 2009; 108(3-4):272-85.

21. Gofar N, Lee ML, Kassim A. Response of Suction Distribution to Rainfall Infiltration in Soil Slope. Electronic Journal of Geotechnical Engineering. 2008; 13E:13.

22. Rahardjo H, Lee TT, Leong EC, Rezaur RB. A Flume for Assessing Flux Boundary in rainfall-induced slope failure studies. Geotechnical Testing Journal. 2004; 27(2).

23. Ng CWW, Zhan LT, Bao CG, Fredlund DG, Gong BW. Performance of an unsaturated expansive soil slope subjected to artificial rainfall infiltration. Geotechnique. 2003; 53(2), 14.

24. Rees SW, Ali N. Tree induced soil suction and slope stability. Geomechanics and Geoengineering. 2012; 7(2):103-13.

25. Kassim A, Gofar N, Lee LM, Rahardjo H. Modeling of suction distributions in an unsaturated heterogeneous residual soil slope. Engineering Geology. 2012; 131-132(0):70-82.

26. Godt JW, Baum RL, Lu N. Landsliding in partially saturated materials. Geophysical Research Letters. 2009; 36(2):L02403.

27. Lu N, Godt J. Infinite slope stability under steady unsaturated seepage conditions. Water Resources Research. 2008; 44(11):W11404.

28. Khalili N, Khabbaz MH. A unique relationship for $\chi$ for the determination of the shear strength of unsaturated soils. Geotechnique. 1998; 48(5):681-7.

29. Fredlund DG, Morgenstern NR, Widger RA. The shear strength of unsaturated soils. Canadian Geotechnical Journal. 1978; 15(3):313-21. 
30. Bishop AW. The Principle of Effective Stress. Teknisk Ukeblad. 1959; 106(39):859- 63.

31. Lu N, Likos WJ. Unsaturated Soil Mechanics Hoboken. New Jersey: John Wiley \& Son, Inc.; 2004. p. 556.

32. Lu N, Likos WJ. Suction Stress Characteristic Curve for Unsaturated Soil. Journal of Geotechnical and Geoenvironmental Engineering. 2006; 132(2):131-42.

33. BSI. Methods of Test for Soils for Civil Engineering Purposes (BS 1377:Part 1-9). London: British Standards Institution; 1990.

34. Fredlund DG, Xing A, Fredlund MD, Barbour SL. The relationship of the unsaturated soil shear to the soil-water characteristic curve. Canadian Geotechnical Journal. 1996; 33(3):440-8.

35. Fredlund DG. The Stability of Slopes with Negative Pore water pressure. The Ian Boyd Symposim on Modern developments in Geomechanics; 1995.

36. Fratta D, Aguettant J, Roussel-Smith L. Introduction to Soil Mechanics Laboratory Testing 2007. New York: CRC Press, Taylor and Francis Group; 2007.

37. ASTM. Standard Test Methods for Determination of the Soil Water Characteristic Curve for Desorption Using Hanging
Column, Pressure Extractor, Chilled Mirror Hygrometer, or Centrifuge, Designation: D6836. Designation D6836. West Conshohocken, United States; 2008.

38. Leong EC, Rahardjo H. Permeability Functions for Unsaturated Soils. Journal of Geotechnical and Geoenvironmental Engineering. 1997; 123(12):1118-26.

39. Van Genuchten MT. A closed-form Equation for Predicting the Hydraulic Conductivity of Unsaturated Soils. Soil Science Society of America Journal. 1980; 44(5):892-8.

40. Geo-Slope International. SEEP/W User's guide for finite element seepage analysis. Geo-Slope International Ltd. Calgary, Alta2007a.

41. Geo-Slope International. SLOPE/W User's guide for slope stability analysis. Geo-Slope International Ltd. Calgary, Alta Canada 2007b.

42. Gofar N, Lee ML. Extreme Rainfall Characteristics for Surface Slope Stability in the Malaysian Peninsular. Georisk. 2008; 2(2):13.

43. Yang H, Rahardjo H, Wibawa B, Leong EC. A Soil Column Apparatus for Laboratory Infiltration Study. ASTM geotechnical testing journal. 2004; 27(4):347-55. 